\title{
Translational Strategies for Enhancing Motor and Sensory Recovery after Nerve Injury or Reconstruction
}

\section{Kevin J Zuo*}

Division of Plastic \& Reconstructive Surgery, University of Toronto, Canada

*Corresponding author: Kevin J Zuo, MD, Division of Plastic \& Reconstructive Surgery, University of Toronto, Toronto, ON, Canada, Tel: 6479974586; E-mail: kevin.zuo@mail.utoronto.ca

\section{Mini Review}

Volume 1 Issue 1

Received Date: November 03, 2017

Published Date: November 22, 2017

DOI: $10.23880 /$ ijtps-16000107

\section{Abstract}

Thousands of patients suffer peripheral nerve injuries annually that lead to motor disability, dysesthesias, neuropathic pain, and lost economic productivity. The slow rate of nerve regeneration in humans of approximately $1 \mathrm{~mm} /$ day is associated with unpredictable and often incomplete end organ reinnervation. This brief review summarizes important research directions to improve outcomes of peripheral nerve injury and repair.

Abbreviations: ES: Electrical Stimulation; MUNE: Motor Unit Number Estimation; PNA: Processed (Decellularized) Nerve Allografts; cAMP: Cyclic Adenosine Monophosphate; BDNF: Brain-Derived Neurotrophic Factor; FDA: Food and Drug Administration.

\section{Introduction}

An ongoing challenge of many plastic surgery procedures is that of enhancing nerve regeneration to maximize motor and sensory recovery. Despite advancements in plastic surgery with vascularized composite allotransplantation, smart prosthetics, tissue engineering, robotics, and novel implant biomaterials, whenever peripheral nerves are injured or repaired, a major rate limiting step is the innate capacity of individual axons in the proximal nerve stump to sprout and regenerate to achieve end organ reinnervation. At the cellular level, multiple factors may affect the success of axon regrowth: neurotrophic factors, neurotropism (growth of axons down correct pathways), preferential motor reinnervation, revascularization, and fibrosis. In particular, nerve regrowth in settings of delayed repair or across long distances are significant challenges as individual neurons undergo chronic axotomy (a neuron cell body not in contact with its peripheral end organ, leading to loss of regenerative capacity) and chronic denervation (Schwann cells in the distal nerve stump not in contact with the neuron cell body, leading to loss of progressive atrophy, loss of proliferative and migratory ability, and an overall inability to support axon regrowth from the proximal stump) [1]. Incomplete or inappropriate nerve regeneration can lead to a host of morbid consequences, including neuropathic pain from neuroma formation, altered sensation following breast reconstruction, incomplete motor reinnervation in hand transplantation or synkinesis from misdirected axonal growth [2]. A theme present in many plastic surgery procedures is the restoration of function and quality of life, and thus the need to improve outcomes after peripheral nerve injury or repair remains a vigorous area of research. 


\section{International Journal of Transplantation \& Plastic Surgery}

Brief electrical stimulation (ES) for 1 hour at $20 \mathrm{~Hz}$ has been shown to accelerate recovery after nerve injury in various animal models, including facial nerve, sciatic nerve, common peroneal nerve, and femoral nerve [3-6]. The effects of ES appear to accelerate the rate of axon crossing of suture sites, as opposed to increasing the innate rate of regeneration of $1-3 \mathrm{~mm} /$ day in rodents [7]. The cellular effects of ES are exerted proximally in the cell body, by upregulating factors such as GAP-43, BDNF, and cAMP. Importantly, stimulation periods of 1 hour or greater are equally effective in motoneuron recovery, but sensory nerve recovery is optimal at 1 hour and no longer, due to downregulation of trkB expression [8]. Experience of brief ES in human studies, while limited, has been logistically feasible and with very promising outcomes. One hour of $20 \mathrm{~Hz}$ ES immediately following carpal tunnel release in patients with electrophysiologic evidence of chronic median nerve compression neuropathy led to significant improvements in motor unit number estimation (MUNE), terminal motor latency, and sensory nerve conduction values [9]. Dramatic improvement in sensory modalities was noted with brief ES following digital nerve repair, while brief ES following cubital runnel release resulted in increased MUNE, grip strength and key pinch strength $[10,11]$. Brief ES is currently being investigated for restoration of sensation after alloplastic breast reconstruction [12]. In a different paradigm, selective ES of peripheral nerves has also shown effectiveness in spinal cord injury patients to restore mobility, as well as respiratory, bladder, and bowel functions [13].

Nerve substitutes are an important resource for reconstruction of gap defects when autograft is limited or not available. Fresh nerve allotransplantation was and remains an area of great interest. Early experimental studies in rodents showed promising results, with histomorphometric measures of nerve regeneration and functional measures of target reinnervation comparable to that of autologous nerve grafts [14-19]. Reports of human studies of gaps as long as $37 \mathrm{~cm}$ similarly produced excellent outcomes. The main barrier to greater application has been the need for systemic immunosuppression to prevent allograft rejection. The use of cyclosporin A or tacrolimus (FK506) was necessary to prevent immune activation and fibrotic degeneration of the allograft. Interestingly, unlike other forms of tissue allotransplantation, immunosuppression for nerve allotransplants is transient and may be discontinued after regenerating host axons have traversed the graft without loss of function [20]. Nevertheless, the months to years' long course of "temporary" immunosuppression has been a barrier to greater acceptance, for fear of eliciting systemic toxicity upon the patient. Fortunately, there have been important advances in nerve substitutes such as biosynthetic conduits and processed (decellularized) nerve allografts (PNA), which are readily available "off the shelf." Since the FDA approval in 2007 of AxoGen's Avance PNA, over 15,000 have been implanted in humans. Excellent clinical outcomes have been reported for smallcalibre nerve gap defects up to $30-40 \mathrm{~mm}$ in length [2123]. Reports for larger-calibre and longer nerve gaps have had variable results [24-26]. Promising future strategies include supplementation of PNAs with neurotrophic factors, Schwann cells, or stem cells to restore a more biologic environment for regenerating axon growth cones [27-29].

Finally, novel methods of local drug delivery have potential for improving nerve regeneration [30-32]. In the case of hand transplants, tacrolimus given as part of the immunosuppression protocol resulted in unexpectedly rapid nerve regeneration and target reinnervation [33]. In order for tacrolimus to be used more widely, its neuroenhancing effects must be isolated from its immunosuppressive effects. Hydrogel delivery systems with encapsulation of a drug in microspheres with predictable release kinetics offer a promising avenue for targeted and sustained neurotrophic drug delivery [34].

Advancements in strategies to enhance nerve regeneration such as electrical stimulation, nerve substitutes, and local drug delivery will play an important role in optimizing outcomes after progressively more advanced transplantation procedures, brain-machine interfaces, biomaterials, and fundamental plastic surgeries such as compression neuropathy and breast reconstruction.

\section{References}

1. Fu SY, Gordon T (1997) The cellular and molecular basis of peripheral nerve regeneration. Mol Neurobiol 14(1-2): 67-116.

2. Chan KM, Curran MW, Gordon T (2016) The use of brief post-surgical low frequency electrical stimulation to enhance nerve regeneration in clinical practice. The Journal of physiology 594(13): 35533559.

3. Mendez A, Seikaly H, Biron VL, Zhu LF, Cote DW (2016) Brief electrical stimulation after facial nerve transection and neurorrhaphy: a randomized prospective animal study. J Otolaryngol Head Neck Surg 45: 7. 


\section{International Journal of Transplantation \& Plastic Surgery}

4. Huang J, Zhang Y, Lu L, Hu X, Luo Z (2013) Electrical stimulation accelerates nerve regeneration and functional recovery in delayed peripheral nerve injury in rats. Eur J Neurosci 38(12): 3691-3701.

5. Elzinga K, Tyreman N, Ladak A, Savaryn B, Olson J, et al. (2015) Brief electrical stimulation improves nerve regeneration after delayed repair in Sprague Dawley rats. Exp Neurol 269: 142-153.

6. Al-Majed AA, Brushart TM, Gordon T (2000) Electrical stimulation accelerates and increases expression of BDNF and trkB mRNA in regenerating rat femoral motoneurons. Eur J Neurosci 12(12): 4381-4390.

7. Singh $B, X u$ QG, Franz CK, Zhang R, Dalton $C$, et al. (2012) Accelerated axon outgrowth, guidance, and target reinnervation across nerve transection gaps following a brief electrical stimulation paradigm. J Neurosurg 116(3): 498-512.

8. Geremia NM, Gordon T, Brushart TM, Al-Majed AA, Verge VM (2007) Electrical stimulation promotes sensory neuron regeneration and growth-associated gene expression. Exp Neurol 205(2): 347-359.

9. Gordon T, Amirjani N, Edwards DC, Chan KM (2010) Brief post-surgical electrical stimulation accelerates axon regeneration and muscle reinnervation without affecting the functional measures in carpal tunnel syndrome patients. Exp Neurol 223(1): 192-202.

10. Wong JN, Olson JL, Morhart MJ, Chan KM (2015) Electrical stimulation enhances sensory recovery: a randomized controlled trial. Ann Neurol 77(6): 9961006.

11. Power HA, Morthart MJ, Olson JL, Chan KM (2016) Electrical Stimulation Enhances Axon Regeneration And Functional Recovery Following Cubital Tunnel Surgery In Humans - A Randomized Controlled Trial. Abstract Session. ASPN Annual Meeting.

12. Senger JL, Chan KM (2017) Electrical Stimulation for Improving Postoperative Breast Sensation. ClinicalTrials.gov.

13. Hamid S, Hayek R (2008) Role of electrical stimulation for rehabilitation and regeneration after spinal cord injury: an overview. Eur Spine J 17(9): 1256-1269.

14. Midha R, Evans PJ, Mackinnon SE, Wade JA (1993) Temporary immunosuppression for peripheral nerve allografts. Transplantation proceedings $25(1 \mathrm{Pt} 1)$ : 532-536.

15. Midha R, Mackinnon SE, Evans PJ, Best TJ, Hare GM, et al. (1993) Comparison of regeneration across nerve allografts with temporary or continuous cyclosporin A immunosuppression. Journal of neurosurgery. 78(1): 90-100.

16. Midha R, Mackinnon SE, Becker LE (1994) The fate of Schwann cells in peripheral nerve allografts. J Neuropathol Exp Neurol 53(3): 316-322.

17. Udina E, Gold BG, Navarro X (2004) Comparison of continuous and discontinuous FK506 administration on autograft or allograft repair of sciatic nerve resection. Muscle Nerve 29(6): 812-822.

18. Bain JR, Mackinnon SE, Hudson AR, Falk RE, Falk JA, et al. (1988) The peripheral nerve allograft: an assessment of regeneration across nerve allografts in rats immunosuppressed with cyclosporin A. Plast Reconstr Surg 82(6): 1052-1066.

19. Mackinnon SE, Hudson AR, Bain JR, Falk RE, Hunter DA (1987) The peripheral nerve allograft: an assessment of regeneration in the immunosuppressed host. Plast Reconstr Surg 79(3): 436-446.

20. Mackinnon SE, Doolabh VB, Novak CB, Trulock EP (2001) Clinical outcome following nerve allograft transplantation. Plast Reconstr Surg 107(6): 14191429.

21. Isaacs J, Browne T (2014) Overcoming short gaps in peripheral nerve repair: conduits and human acellular nerve allograft. Hand (N Y) 9(2): 131-137.

22. Rinker B, Vyas KS (2014) Clinical applications of autografts, conduits, and allografts in repair of nerve defects in the hand: current guidelines. Clin Plast Surg 41(3): 533-550.

23. Rinker BD, Ingari JV, Greenberg JA, Thayer WP, Safa B, et al. (2015) Outcomes of short-gap sensory nerve injuries reconstructed with processed nerve allografts from a multicenter registry study. J Reconstr Microsurg 31(5): 384-390.

24. Saheb-Al-Zamani M, Yan Y, Farber SJ, Hunter DA, Newton P, et al. (2013) Limited regeneration in long acellular nerve allografts is associated with increased Schwann cell senescence. Exp Neurol 247: 165-177. 


\section{International Journal of Transplantation \& Plastic Surgery}

25. Poppler LH, Ee X, Schellhardt L, Hoben GM, Pan D, et al. (2016) Axonal Growth Arrests After an Increased Accumulation of Schwann Cells Expressing Senescence Markers and Stromal Cells in Acellular Nerve Allografts. Tissue Eng Part A 22(13-14): 949961.

26. Rinker B, Zoldos J, Weber RV, Ko J, Thayer W, et al. (2017) Use of Processed Nerve Allografts to Repair Nerve Injuries Greater Than $25 \mathrm{~mm}$ in the Hand. Ann Plast Surg 78(6S Suppl 5): S292-S295.

27. Tajdaran K, Gordon T, Wood MD, Shoichet MS, Borschel GH (2016) A glial cell line-derived neurotrophic factor delivery system enhances nerve regeneration across acellular nerve allografts. Acta Biomater 29: 62-70.

28. Jesuraj NJ, Santosa KB, Macewan MR, Moore AM, Kasukurthi R, et al. (2014) Schwann cells seeded in acellular nerve grafts improve functional recovery. Muscle Nerve 49(2): 267-276.

29. Walsh SK, Gordon T, Addas BM, Kemp SW, Midha R (2010) Skin-derived precursor cells enhance peripheral nerve regeneration following chronic denervation. Exp Neurol 223(1): 221-228.
30. Wood MD, Moore AM, Hunter DA, Tuffaha S, Borschel $\mathrm{GH}$, et al. (2009) Affinity-based release of glialderived neurotrophic factor from fibrin matrices enhances sciatic nerve regeneration. Acta Biomater 5(4): 959-968.

31. Wood MD, MacEwan MR, French AR, Moore AM, Hunter DA, et al. (2010) Fibrin matrices with affinitybased delivery systems and neurotrophic factors promote functional nerve regeneration. Biotechnol Bioeng 106(6): 970-979.

32. Wood MD, Kim H, Bilbily A, Kemp SW, Lafontaine C, et al. (2012) GDNF released from microspheres enhances nerve regeneration after delayed repair. Muscle Nerve 46(1): 122-124.

33. Tung TH (2010) Tacrolimus (FK506): Safety and Applications in Reconstructive Surgery. Hand (N Y) 5(1): 1-8.

34. Tajdaran K, Shoichet MS, Gordon T, Borschel GH (2015) A novel polymeric drug delivery system for localized and sustained release of tacrolimus (FK506). Biotechnol Bioeng 112(9): 1948-1953. 